\title{
PRÁTICAS DISCURSIVAS NA CONSTRUÇÃO DE UMA GASTRONOMIA POLIFÔNICA
}

\section{DISCURSIVE PRACTICES IN THE CONSTRUCTION OF A POLYPHONIC GASTRONOMY}

\section{IVANA BENEVIDES DUTRA MURTA}

Bacharel em Turismo pelo Departamento de Geografia da Universidade Federal de Minas Gerais (UFMG).

Pesquisadora do Núcleo de Estudos Organizacionais e Sociedade (Neos) da Faculdade de Ciências Econômicas da Universidade Federal de Minas Gerais. Rua Augusto Souza Coutinho, 896 - Belo Horizonte - MG - Brasil - CEP 30860-140 E-mail: ivanabenevides@yahoo.com.br

\section{MARIANA MAYUMII PEREIRA DE SOUZA}

Mestranda do Programa de Pós-graduação em Administração da Universidade Federal de Minas Gerais (UFMG).

Pesquisadora do Núcleo de Estudos Organizacionais e Sociedade (Neos) da Faculdade de Ciências Econômicas da Universidade Federal de Minas Gerais. Rua Elói Mendes, 371, Sagrada Família - Belo Horizonte - MG - Brasil - CEP 31030-110

E-mail:mariana_mayumi@yahoo.com.br

\section{ALEXANDRE DE PÁDUA CARRIERI}

Doutor em Administração pelo Centro de Pós-graduação e Pesquisa em Administração da Universidade Federal de Minas Gerais (UFMG).

Professor do Programa de Graduação e do Centro de Pós-Graduação e Pesquisa em Administração da Universidade Federal de Minas Gerais. Avenida Antônio Carlos, 6.627, sala 4071, Pampulha - Belo Horizonte - MG - Brasil - CEP 31270-901

E-mail: alexandre@cepead.face.ufmg.br 


\section{RESUMO}

Objetivamos neste trabalho contextualizar o desenvolvimento da gastronomia e as mudanças de significado espacial, observando as táticas e estratégias envolvidas nesse processo. As práticas cotidianas reconstroem continuamente os significados da culinária, e, no caso de Macacos, distrito mineiro, a $30 \mathrm{~km}$ de Belo Horizonte, observamos que o mosaico de ofertas gastronômicas reflete tais práticas e projeta certa identidade do distrito aos turistas. Macacos apareceu como um polo ou roteiro gastronômico regional a partir de finais do século XX, mas já se desenvolveu bastante nessa área e conta com restaurantes de culinária mineira e internacional. Nesse contexto, procuramos saber: como se constroem as estratégias e táticas gastronômicas em Macacos? Para tanto, foram feitas consultas documentais, consultas às cartas dos restaurantes e entrevistas com donos e funcionários. Ao final, encontramos que a polifonia era a estratégia em todas as atividades gastronômicas em Macacos. Todavia, percebemos uma diferenciação associada à origem dos donos dos restaurantes: os empreendedores autóctones tendem a trabalhar com a elaboração de comida típica mineira, ao passo que os forasteiros, em geral, fazem questão de se classificarem como inseridos em uma gastronomia internacional. Na coexistência do típico e do exótico, a polifonia e a pictoricidade são práticas evidenciadas.

\section{PALAVRAS-CHAVE}

Práticas estratégicas; Práticas discursivas; Gastronomia polifônica; Turismo; Dinâmica espacial.

\section{ABSTRACT}

In this paper, we aimed to contextualize the gastronomic development and changes in spatial meanings, considering the tactics and strategies involved in this process. 
The everyday practices reconstruct continuously the culinary meanings and, in the case of the district of Macacos, a city in the state of Minas Gerais, $30 \mathrm{~km}$ from Belo Horizonte, we observed that a mosaic of gastronomic offers reflects the everyday practices and projects certain identity of the district to tourists. Macacos became a regional gastronomic pole or route at the end of twentieth century, but it has already developed a lot in this sector and counts on several restaurants of regional and international food. In this context, we wanted to know: how gastronomic strategies and tactics are built in Macacos? In order to answer this question, we analyzed documents, the restaurants' menu and we interviewed the restaurants' owners and employees. By the end, we found out that polyphony was the strategy in all gastronomic activities in Macacos. However, we observed a differentiation associated to the restaurant owners' origin: the entrepreneurs from Macacos tended to work with regional food and the entrepreneurs from outside the district tended to work with what they classified as "international food". In the coexistence of typical and exotic, polyphony and pictoriality are relevant practices.

\section{KEYWORDS}

Strategic practices; Discursive practices; Polyphonic gastronomy; Tourism; Spatial Dynamics.

\section{INTRODUÇÃO}

Neste trabalho, almejamos contextualizar e entender as relações entre gastronomia e as práticas cotidianas, passando por aspectos ligados à atividade turística. Nas análises das práticas discursivas empreendidas pelos donos e chefs de restaurantes de Macacos, objetivamos compreender os usos de estratégias e táticas e as relações entre os espaços simbólicos da gastronomia e da culinária comum, no contexto da conversão da comida em produto turístico. Com base nesse objetivo central, foi possível refletir sobre o desenvolvimento da gastronomia em Macacos, sobre as táticas e estratégias envolvidas nela e sua relação com a identidade projetada da região aos turistas. As práticas cotidianas transformam continuamente a culinária, inclusive o discurso em torno dela acaba por configurar uma tática ou uma estratégia. A diferenciação entre o espaço das táticas da cozinha comum e o espaço das estratégias da alta gastronomia se faz clara na linguagem, o que se denota tanto pelos utensílios, pelas operações envolvidas, como pelos produtos finais, por meio da nomeação e/ou da aparência. 
Segundo Oliveira (2007, p. 262, tradução nossa), "em todas as partes já se começa a observar pessoas que viajam para experimentar, degustar e provar novos sabores, tanto em restaurantes como em feiras gastronômicas, ceias medievais e muitos outros eventos".

Ainda que a gastronomia não seja, na maioria das vezes, a motivação primária da ida de turistas aos destinos, em alguns lugares ela aparece revestida de tamanha relevância turística que compete aos pesquisadores compreender a representação desse segmento, observando as várias questões a ele relacionadas, que podem desencadear estudos de cunho social, territorial, econômico, ambiental, entre outros enfoques. Nesse sentido, o presente trabalho se propõe a suprir a lacuna sobre os estudos que focam as práticas gastronômicas como atividade de exploração turística. Observa-se escassez de estudos empíricos sobre essa temática. Espera-se, portanto, contribuir para a compreensão das estratégias e táticas empreendidas nesse segmento e quais os impactos de ambas nos espaços e sujeitos envolvidos. Entende-se que a conversão da comida em produto turístico, por estar investida de práticas estratégicas, finda por transformar sujeitos e espaços de que depende essa transformação.

Escolhemos fazer este estudo em São Sebastião das Águas Claras, primeiramente, por ser um destino de Minas Gerais que tem sido projetado como "polo gastronômico”. Mas não somente por essa projeção identitária, também por já ser reconhecido em Belo Horizonte (capital do referido Estado) como um lugar onde há muitos restaurantes de boa qualidade para visitar aos fins de semana. São Sebastião das Águas Claras é um distrito localizado no município de Nova Lima. É mais conhecido como Macacos, por causa do Ribeirão dos Macacos que corta a cidade (DRUMMOND, 2008, p. 23), sendo essa denominação mais usada também neste artigo.

Este trabalho está dividido em seis seções, além desta introdução. Na próxima seção, tratamos das práticas cotidianas, constituídas por estratégias e táticas, mais especificamente das práticas culinárias. Na terceira seção, conceituamos turismo gastronômico e procuramos contextualizar o termo em relação a nosso estudo. Em seguida, a quarta seção reconstitui um breve histórico da transformação da comida em atrativo turístico em Macacos, recorrendo, para tanto, a documentos, bibliografias e à própria fala de habitantes. Na quinta seção, são expostos os procedimentos metodológicos da pesquisa. Na sexta seção, analisamos o contexto por meio das falas dos chefs e/ou chefs-proprietários. Na sétima seção, apresentamos uma síntese da análise e as considerações finais. 


\section{ESTRATÉGIAS E TÁTICAS}

Para Certeau (I994), o cotidiano é construído por meio de bricolagens dos vários indivíduos que compartilham de um mesmo espaço. Os dominados seriam capazes de se apropriar da esfera simbólica constituída pelos dominantes e transformá-la, ressignificá-la, de acordo com suas próprias necessidades e possibilidades. Dessa forma, constituem-se movimentos de resistência por parte dos dominados, mas sem que isso se transforme necessariamente em ameaça ao poder simbólico dos dominantes do território.

Certeau (I994) contribui para a compreensão do conceito de estratégia de forma inovadora, pois introduz a noção da "arte do fazer", levando ao questionamento do foco desse fazer no interior de territórios. Para o autor, a despeito da existência de sujeitos no lugar com o poder para definir objetivos, coexiste uma infinidade de outros interesses convergentes ou divergentes ao poder dominante. Com base em tais ideias, desenvolvem-se os conceitos de estratégia e tática para compreender a natureza da multiplicidade de práticas que constroem o cotidiano. As estratégias são cálculos de relações de força que se tornam possíveis a partir do momento em que um sujeito de querer e poder é isolável das exterioridades. Ou seja, o modelo estratégico presume a existência de um lugar circunscrito, no qual existem relações de dominação e regras prescritivas de conduta. Já a tática seria "um cálculo que não pode contar com um próprio, nem, portanto, com uma fronteira que distingue o outro com totalidade visível" (CERTEAU, I994, p. 46).

Nesse sentido, as táticas são contextuais e oportunistas, frutos da inteligência cotidiana. São práticas que se aproveitam de certa situação para gerar resultados imediatos. No espaço do outro, as táticas se aproveitam do tempo para captar possibilidades de ganho. Enquanto as estratégias se relacionam com o poder exercido em um lugar próprio ou em uma instituição, as táticas se relacionam com a astúcia popular. A estratégia é destinada ao acúmulo futuro, à prescrição e ao controle. Já a tática é contextual e efêmera. "O que ela ganha, não o guarda" (CERTEAU, I994, p. 47). Com base na definição dos conceitos de estratégia e tática, Certeau (I994) estabelece as relações de poder existentes dentro de determinados espaços.

\subsection{ESTRATÉGIAS E TÁTICAS NO ESPAÇO SIMBÓLICO DA COZINHA}

Tendo em vista os conceitos de estratégia e tática, a prática culinária deve ser analisada sob o prisma de seus elementos simbólicos e das relações de poder 
que se instauram sobre quem cozinha e quem come. Montoro (s. d.) e Giard (2003) observam que comer vai muito além da simples necessidade biológica, pois faz parte da relação entre as pessoas e o mundo, sendo uma das referências fundamentais no espaço-tempo. Ademais, as práticas envolvidas no preparo e no consumo da comida são altamente variáveis entre diferentes sociedades, o que demonstra a influência dos aspectos culturais, econômicos e históricos na culinária de determinada região. Nesse sentido, as preferências alimentares em determinado sistema social, em um dado momento, variam de acordo com as representações sociais do que é comestível, combinável, saudável, requintado, do que está na moda, ou é próprio para certa estação do ano, ou etapa da vida.

Os hábitos alimentares de determinada região não podem ser analisados sem se levar em consideração a dimensão diacrônica das histórias que se acumulam por detrás do mosaico de sabores e texturas, pois corre-se o risco de procurar falsas coerências internas. O que comemos atualmente, quem prepara e como prepara é fruto de toda uma história de dominação, imbuída de significados simbólicos. Isso pode ser analisado nas diferenças dos hábitos alimentares entre classes sociais, nos significados dos pratos para determinadas ocasiões, no uso crescente de instrumentos tecnológicos para cozinhar, entre outros aspectos (GIARD, 2003; FRANCO, 2004).

Giard (2003) observa que o espaço simbólico da cozinha tem passado por distinções a partir da distribuição de papéis entre homens e mulheres na culinária. Os homens, quando cozinhavam, assumiam o papel dos grands chefs e ocupavam o espaço da excelência e do extremo requinte. Nesse sentido, na França do século XVIII, construiu-se o discurso da gastronomia, como código teórico da prática culinária, que exerceu a triagem, classificou e nomeou as riquezas do comer bem. Houve o movimento de elaboração de uma cultura culinária, reforçado pela mídia e literatura, que legitimou pratos e excluiu mulheres do ato de cozinhar em grandes restaurantes. Os cozinheiros-artistas seriam todos homens, pois cozinhar se tornou "gastronomia", um trabalho de escrita que precisa, apura e teoriza.

Enquanto o discurso da gastronomia se apropriava do glamour do ato de cozinhar com sofisticação, requinte e ingredientes selecionados, a cozinha comum diária, exercida por mulheres e pertencente à esfera privada das famílias, continuava sua prática cotidiana silenciosa, elementar, humilde, obstinada, repetida no tempo e no espaço. Cozinhar no cotidiano é considerado tarefa simples e até um pouco tola. Entretanto, por detrás da uniformidade do cotidiano e da tradição, constrói-se diariamente uma "montagem sutil de gestos, de ritos e de códigos, de ritmos e de opções, de hábitos herdados e de costumes repetidos" (Giard, 2003, p. 234). O espaço da cozinha comum é o espaço anônimo das táticas, do improviso e, muitas vezes, o único lugar de inventividade possível para sujeitos, notadamente, mulheres. Contrapõe-se, portanto, ao espaço da gastronomia, 
dominado pelas estratégias de homens, pelo acesso aos recursos necessários e pelo domínio das condições de produção da comida.

A diferenciação entre tais espaços se faz clara na linguagem, que denota os ingredientes; os utensílios; as operações, verbos de ação e descrições; e os produtos finais, a nomeação dos pratos obtidos. O discurso da gastronomia, sendo estratégico, exige a distinção do ordinário, do que é consumido popularmente, exige também preparo sofisticado. Assim, seu objetivo é alcançado: a valorização do produto final, como algo que carrega significados simbólicos que vão além do simples ato de comer, para simbolizar riqueza, prazer e arte (GIARD, 2003; MONTORO, s. d.).

Analisando a nomenclatura dos pratos, por exemplo, na esfera privada da vida das pessoas comuns, observamos que os pratos não têm nomes obscuros, denotam simplesmente os ingredientes e os modos de preparo. Quem inventa os pratos não se pretende inventor de algo e, por isso, não se preocupa em nomear sua criação. A pessoa apenas "se virou com algumas coisas", sem o interesse de que sua ideia seja conhecida além do círculo familiar. Já no caso de restaurantes, quanto mais requintados, mais pomposos e enigmáticos são os nomes dos pratos. Ao cliente, torna-se necessário recorrer ao maître ou garçom para saber o que são realmente as composições dos pratos ou se pede às cegas palavras desconhecidas para não "fazer feio" (GIARD, 2003).

Portanto, os nomes pomposos dos pratos fazem parte do discurso gastronômico e surgem notadamente com a ascensão da burguesia. Os chefs, que antes atendiam a nobreza, passaram a ter que bajular o paladar burguês com nomes do vocabulário nobre e principesco, para que os burgueses se sentissem elevados da condição plebeia. Contudo, a distinção linguística entre gastronomia e cozinha comum, com o passar do tempo, nem sempre figura tão clara. Observam-se movimentos de apropriação de elementos discursivos de um espaço para outro. Pratos da gastronomia mais bem-sucedidos passaram aos poucos a ser conhecidos por todos, integrando a ordem dos nomes comuns, como molho béchamel e charlotte. Entre o discurso da gastronomia e a cozinha comum, existem também os pratos cujos nomes remetem à sua região geográfica. São o meio-termo entre os nomes obscuros e nobres da gastronomia e os modestos e descritivos da culinária ordinária (GIARD, 2003).

Dessa forma, a gastronomia e a culinária comum constituem dois discursos diferentes, mas que, frequentemente, dialogam entre si. A alimentação pode ser entendida, portanto, como uma forma de linguagem, a partir da qual é possível construir sentidos variados que se localizam em um espaço e em um tempo. No atual contexto de globalização, associado à compressão espaço-tempo (BRITO, 2006) e ainda considerando a localização do lugar investigado neste trabalho, fazse imprescindível falar sobre a polifonia, conceito esse proveniente das reflexões 
do Círculo de Bakhtin (I920-I939), mas adaptado à lógica do presente estudo. Ao apropriarmos das ideias de Certeau (I994), Giard (2003) e Bakhtin (I999), fizemos uma analogia da comida não apenas como linguagem, mas também como discurso. Nesse sentido, a comida é inerentemente dialógica, ou seja, é resultado de uma relação transindividual de significado. A perspectiva dialógica foi aqui escolhida pelo fato de a comida em Macacos assumir sentidos diferentes de acordo com os topoi, ou lugares de enunciação (DUCROT, I989).

\section{ENTRE ALIMENTAR E COMER - PRÁXIS GASTRONÔMICA NA ATIVIDADE TURÍSTICA}

Numa abordagem antropológica, ao se considerar o turismo como desejo humano profundo de conhecer o outro, com a possibilidade recíproca de que com isso o indivíduo possa conhecer a si mesmo (MCKEAN, I977 apud BURNS, 2004), viajar seria uma possibilidade de transformação pessoal pelo movimento (PELEGRINI, I997). Quem viaja se transforma em virtude daquilo que encontra em seu caminho (pessoas, atrativos, manifestações culturais etc.). Mas também transforma quem o recebe (pessoas, lugares, rituais etc.), sendo o turismo, portando, uma atividade social, transformadora da cotidianidade e dos espaços, por meio das viagens empreendidas pelo ser humano.

É imprescindível dizer que, para uma compreensão mais próxima da abordagem de turismo gastronômico que se dá neste trabalho, há uma diferença importante a ser destacada entre turistas que utilizam o sistema de alimentação (bares, restaurantes e lanchonetes etc.) por necessidade e turistas que selecionam o destino com base nas relações com a gastronomia (OLIVEIRA, 2007). Assim, a grande questão a ser colocada é da alimentação para suprimento de necessidades, algo mais próximo à cozinha ordinária, ou da comida como atrativo turístico, mais pertinente ao discurso da gastronomia.

A gastronomia como atrativo turístico tem seu começo de desenvolvimento já após a Segunda Guerra Mundial, pois, tal como afirma Franco (2004, p. 230), os guias turísticos impressos que surgiram nessa época, "além de considerações gastronômicas propriamente ditas, descrevem os restaurantes, sua decoração, ambiente e o estilo da cozinha de seus chefs". Esse fato é ainda intensificado nos últimos anos porque "as viagens de automóvel e os guias turísticos favorecem a descoberta das cozinhas regionais, a descentralização dos modelos culinários e a associação do turismo à gastronomia" (FRANCO, 2004, p. 230). Enfim, o segmento do turismo gastronômico já é um fato e vem sendo reconhecido e analisado na academia.

Partindo de uma perspectiva técnica, o turismo gastronômico seria: 
[...] a visita a produtores primários ou secundários de alimentos, participação em festivais gastronômicos e busca por restaurantes ou lugares específicos em que a degustação de alimentos e toda experiência inerente é a razão principal para viajar (HALL; MITCHELI, 2002 apud OLIVEIRA, 2007, tradução nossa).

No sentido da definição técnica de turismo gastronômico, teríamos as iguarias ou as comidas típicas como relevantes atrações. Mas é imprescindível dizer que, quando falamos aqui das cozinhas típicas ou associadas a determinados espaços, estamos considerando, na verdade, elementos historicamente construídos na cozinha comum, apropriados pelas práticas estratégicas no espaço gastronômico. Isso porque neste trabalho, conforme já exposto, o discurso da gastronomia é entendido de forma dialogal, sendo frequentemente polifônico.

Tal como relatou Franco (2004), com os aviões, com os acordos bilaterais e acordos internacionais, as trocas de produtos e de saberes fazeres se intensificam cada vez mais. E, nesse âmbito, o diálogo entre a gastronomia e a culinária comum de diferentes regiões também se intensifica, o que foi motivado, entre outros fatores, pela saída da mulher para o trabalho, com a questão da moda, entre outras coisas. Nesse contexto, temos a questão segundo a qual "assim como o isolamento acentua as peculiaridades regionais, a dinamização das comunidades gera processo no sentido oposto" (FRANCO, 2004, p. 238). Nesse sentido, como Franco (2004, p. 243) propôs, "a gastronomia do século XX passa por fase de acentuado pluralismo culinário". Esse intenso contato, neste estudo, não implicou homogeneização, mas práticas de hibridismo e mudanças ou rompimento nas e com as tradições.

Assim, poderíamos questionar como a típica comida mineira poderia se converter em atrativo turístico para um público mineiro. Para turistas de fora do Estado, está muito claro que a comida típica mineira seria um importante atrativo gastronômico. No entanto, em que condições ela se converte em gastronomia, ou seja, como algo fora da esfera cotidiana, como um atrativo turístico para os belo-horizontinos que compõem a demanda menos sazonal, ou seja, a demanda dos fins de semana? Trata-se de uma questão importante para se compreender a relação entre gastronomia, práticas cotidianas e turismo em Macacos, e, em certa medida, em Minas Gerais.

\section{COMO TUDO COMEÇOU? POR UM HISTÓRICO DA COMIDA COMO PRODUTO EM MACACOS}

Antes de qualquer histórico estritamente relacionado à gastronomia em São Sebastião das Águas Claras (Macacos), há que se contextualizar a história do dis- 
trito em si, por ser essa história influenciadora das relações desenvolvidas atualmente. Tal como descreve Queiroz (2003), a região de Nova Lima era bastante explorada pela quantidade de ouro que ali se podia encontrar. Com a proibição do trabalho escravo, para trabalhar na busca por vários minerais, deslocaram-se, principalmente, imigrantes ingleses, espanhóis e portugueses para os arredores de Nova Lima (nome esse registrado apenas em I923).

Segundo Villela (I998 apud QUEIROZ, 2003), Macacos era o principal vilarejo da região de Nova Lima, e sua origem remonta à primeira metade do século XVIII. Já em I740, o lugar foi registrado no censo da Vila de Sabará como arraial (LIMA JR., 200I apud QUEIROZ, 2003). O “Ribeirão dos Macacos" concentrava minerais de quatro afluentes, sendo, portanto, um bom lugar para exploração. Ademais, o vilarejo teve seu comércio muito desenvolvido, chegando mercadorias nas tropas que vinham pela Estrada Geral. Com o desenvolvimento do comércio, de acordo com Queiroz (2003) recorrendo novamente a Villela (I998), Macacos se tornou um lugar de pouso também para as tropas de muares que abasteciam a região, por já se ter desenvolvido ali uma infraestrutura mínima. Dessa forma, destacamos como dado muito importante, tal como em vários outros municípios e distritos de Minas Gerais, suas formações associadas à época do trabalho e às necessidades dos garimpeiros, mineradores e tropeiros. Com isso, o vilarejo assumia uma dinamicidade surpreendente, mas, por causa da posterior diminuição dos recursos, acabou parando no tempo. A partir da queda da mineração, o vilarejo viveu em ostracismo, sendo sua economia estagnada, e, com isso, as características arquitetônicas e culturais seguiam sem grandes alterações.

A partir do final do século XX, com a intensificação do uso do espaço de Macacos e arredores para a atividade turística, o distrito recebe injeções financeiras de turistas, de investidores e de pessoas que se mudam para viver no local, pela qualidade de vida e oportunidade de trabalho. Para Queiroz (2003), o turismo apareceu como desordenado e como desestruturador do patrimônio material arquitetônico. E vale dizer que sua dissertação versa sobre o impacto na conservação do patrimônio material. Com a intensificação da atividade turística/excursionista em Macacos, Queiroz (2003) relata as diversas brigas que se desenvolvem, incluindo as relativas ao aumento da especulação imobiliária.

Segundo uma antiga proprietária de restaurante (Eo6), entrevistada neste estudo, há muito tempo que a região de Macacos recebe pessoas de outras localidades, por causa do relevo e das belezas naturais, que são atrativos para praticantes de esportes de aventura, com destaque para trilhas feitas em motos. O desenvolvimento da gastronomia teria se iniciado, então, por meio do público formado por motoqueiros que frequentavam o lugar. Em suas palavras, um pouco da história da gastronomia em Macacos: 
Ah, o restaurante começou aqui na casa de Dona Dica, que é vizinha aqui. Vinha uns motoqueiros pra cá, esse tempo ainda tinha pouco, pouquinho movimento por aqui. [...] Era a casa dela. Ela começou com a casa dela. Eles pediam a ela pra fazer comida. Então ela fazia e eles foram gostando e foi aumentando mais o pessoal, até que ela viu que abrir um restaurante. [...] Ah, era feijão tropeiro, arroz, frango, carne, essas coisas assim. Comida mineira mesmo (Eo6).

Tal como aparece na fala da entrevistada Eo6, também esse início foi registrado por Rodrigues (2008). Segundo a autora, o polo gastronômico resulta de um início à mineira. Isso porque Dona Dica teria sido a primeira a servir comida mineira para os motoqueiros que faziam trilhas na região e que, à hora do almoço, buscavam por um serviço de alimentação no lugar.

Mas fato é que o turismo em Macacos assumiu a reorganização do distrito. Desenvolveu-se ainda mais com o asfaltamento da estrada que conecta Belo Horizonte ao distrito, uma vez que em tempos de chuvas torrenciais ficava intransitável. Nesse sentido, os atrativos naturais do local passaram a ser ainda mais valorizados, permitindo diferentes públicos e não somente atraindo os aventureiros. Nesse contexto, o atrativo gastronômico passa a ser reconhecido e observado, principalmente pelo grande número de restaurantes no local. E, entre tradição e exotismo ${ }^{\mathrm{I}}$, surge Macacos requerendo o título de polo gastronômico. Mas, nesta última frase, quem seria "Macacos"? Trata-se de uma metonímia que representa a parte pelo todo, conforme foi possível entender por meio dos dados de campo, esse "Macacos" compreende os comerciantes, os proprietários de restaurantes, principalmente. Pessoas responsáveis pela enunciação do discurso da gastronomia no distrito, capazes de projetar uma nova identidade para Macacos. Identidade esta, estratégica, atrativa às pessoas de fora. Ao mesmo tempo, nesse processo, silenciam-se as vozes do cotidiano de Macacos, dos habitantes antigos e das donas de casa, autoras anônimas da cozinha comum.

\section{DO PERCURSO DA PESQUISA}

Para a realização deste trabalho, inicialmente foi feita uma pesquisa bibliográfica e documental. Coletaram-se informações na internet e em produções científicas a respeito do distrito de Macacos que, em Belo Horizonte, como mencionado na introdução, já é reconhecido pelos seus restaurantes. Foram revisados sites e alguns guias turísticos que auxiliaram na elaboração de tópicos para serem considerados nos questionários estruturados e para serem tratados nas

Por tradição, entende-se a comida típica mineira. O exótico seria a inserção da gastronomia internacional. 
entrevistas temáticas realizadas com auxílio de roteiro semiestruturado, tanto com moradores da área central do distrito - onde se concentra a maioria dos restaurantes - como com os proprietários de restaurantes ou bares. A coleta de dados terminou quando as respostas começaram a se repetir, o que demonstrava uma representação mais próxima da coletividade que integra os moradores e os empreendedores da área central.

Foram entrevistados ao todo dez representantes de restaurantes e conversamos com vários moradores, entre os quais alguns foram entrevistados. A maioria das entrevistas foi gravada e transcrita na íntegra. A seleção dos participantes foi por conveniência. Houve um esforço em entrevistar pessoas de diferentes tipos de restaurantes, tanto de estabelecimentos mais antigos quanto mais recentes. Entrevistamos oito donos de restaurantes e dois funcionários indicados pelos donos. Ao todo, foram seis mulheres e quatro homens. As conversas com os moradores foram várias. As não gravadas foram registradas em diário de campo. As conversas gravadas foram concedidas por seis moradores, indicados pela comunidade como pessoas antigas e de referência. Também entrevistamos a presidente da associação comercial, que não permitiu gravar sua fala.

É importante destacar ainda que, tendo sido esta pesquisa desenvolvida sob o enfoque qualitativo, nela não se negou de forma alguma a interação entre pesquisadores e sujeitos da pesquisa. Assim, constituímos o corpus também pelas observações registradas por escrito pelos pesquisadores no decorrer das entrevistas ou durante reflexões em momentos informais da pesquisa de campo e em visitas informais ao distrito. Os pesquisadores envolvidos são universitários de Belo Horizonte e costumam frequentar o distrito de Macacos também para apreciar a gastronomia local e as belezas naturais.

As respostas às perguntas foram analisadas de duas maneiras diferentes. A primeira consistiu em identificação de temas que se repetiram nas falas dos entrevistados de maneira explícita. Para subsidiar essa etapa da interpretação dos dados, foi elaborado um mapa de associação de ideias (VERGARA, 2005). Em seguida, após obtermos uma relação dialógica entre as respostas, interpretamos os dados utilizando algumas categorias da análise do discurso, tais como, basicamente: polifonia, implícitos pressupostos e subentendidos (DUCROT, I989; BAKHTIN, I999). Devemos dizer que não foi feita uma análise sintática, tendo-se em vista o objetivo deste artigo, de trabalhar na construção do sentido da gastronomia/culinária como linguagem, associando-a, portanto, às práticas relativas à comida como produto. Justificamos o uso de algumas categorias da análise do discurso aqui pela concepção que norteou o trabalho, da gastronomia, segundo a perspectiva do dialogismo e da polifonia. Dessa forma, encontramos nessa abordagem metodológica uma possibilidade para a interpretação dos sentidos; para tanto, baseamo-nos também nos topoi argumentativos, procurando entender as representações de diferentes grupos de sujeitos em relação à gastronomia. 


\section{O CONTEXTO HOJE}

No período da pesquisa em Macacos, foram contabilizados 32 empreendimentos, entre bares e restaurantes. A oferta gastronômica no local é variada; desde pratos tradicionais da culinária mineira até os mais variados pratos inventados ou influenciados por cozinhas internacionais. Há, nesse sentido, um cenário pictórico da gastronomia, para citar Wölfflin (2000), crítico da arte inclusive mencionado por Bakhtin para fazer uma analogia ao rompimento de limites rígidos entre o discurso do indivíduo e a presença do discurso de outrem na enunciação. Estamos diante de um contexto em que diversas vozes confluem para atender o público, para de fato construir um "discurso gastronômico". Em geral, o turista é belo-horizontino, segundo citado por todos os entrevistados. E foi na mescla entre os diversos ingredientes, na decoração do restaurante, na nomeação dos pratos e na forma de atendimento que se observou a polifonia gastronômica no distrito, visando ao atendimento desse público. Essa libertação em relação ao traço linear, às fronteiras, se dá na medida em que há a incorporação de pratos internacionais, mas alterando-se alguns ingredientes ou mesmo mudando-se o modo de preparo. E também na oferta de um prato internacional, mas com o atendimento voltado para os valores mineiros. Assim como também é possível observar o caráter pictórico referente aos novos nomes ou aos novos modos de usar elementos característicos de "pratos típicos autóctones", tais como o orapro-nóbis ou o cansanção ${ }^{2}$, entre outros. Também esse rompimento com o típico linear foi observado nas mudanças da maneira de preparar, adequando-se ao novo contexto. Estamos falando aqui da cozinha que Giard (2003) denominou de "cozinha comum". No entanto, nessa paisagem de traços que se confundem e se fundem, essa cozinha ganha um caráter pictórico, ela se investe de novo discurso - o gastronômico. A comida mineira, por exemplo, que é historicamente reconhecida por ser muito gordurosa, perde essa característica em Macacos, ao ser adequada, diminuindo o uso de banha de porco e incorporando azeites e criando um novo discurso de retorno do típico e da história. Entre os principais pratos da comida mineira observados nas cartas dos restaurantes, aparecem o feijão tropeiro, o frango caipira acompanhado de cansanção, quiabo ou de ora-pro-nóbis, a feijoada e o mexido. Da cozinha internacional, destacam-se influências espanholas, lusitanas, italianas, mas também têm espaço a árabe, a norueguesa e a marroquina, entre outras.

Cansanção: uma planta urticante, por isso mesmo pouco usada no consumo humano. Quando usada, passa por um tratamento especial. O resultado no prato é uma folha que deixa o aspecto da comida próximo da baba do quiabo. Segundo Eo8: "Ela imita o quiabo, mas é mais gostoso". 
Entendemos que as características e os significados da alimentação são delineadores da historicidade dos lugares ou identificadores de territórios, como brevemente anunciado no referencial teórico. A polifonia evidente nos produtos gastronômicos estudados foi entendida por meio do dialogismo referente ao tema, como uma estratégia de empreendedores da gastronomia, materializada nas vozes e nos usos dos ingredientes de determinados pratos. Foram essas vozes que constituíram a representação que se fez neste artigo e que será mais bem explicitada adiante, visando a uma contextualização geral da situação na qual se encontra Macacos em relação à gastronomia.

A questão do dialogismo em Macacos acaba por induzir à polissemia da gastronomia no distrito. Por polissemia entendemos a construção de diferentes sentidos em torno de um mesmo léxico ou expressão. Essa polissemia está relacionada às representações em torno da polifonia, ela abrange necessariamente a questão dos topoi argumentativos. Assim, ela atinge também a própria formação de sentidos e o entendimento em torno da culinária como elemento cultural dinâmico, porque é socialmente construído e reelaborado nas diversas localizações temporais e espaciais. Dessa maneira, a polissemia resulta de uma interação social. De acordo com Furlanetto (2006, p. 528):

Para encontrar a orientação argumentativa é preciso, então, explorar os topoi convocados. A argumentação, com base nisso, se descreve a partir dos enunciadores apresentados no discurso. Os topoi pressupõem sempre um enunciador, virtual ou não. Eles representam "evidências", vozes na sombra, algo que é fundamentado sem que disso, em geral o locutor se dê conta; funcionam como uma espécie de acordo que serve de premissa (de caráter cultural) - uma memória discursiva.

Entretanto, o mais importante de todos esses deslindamentos foi mesmo compreender que a polifonia em verdade configura uma estratégia de persuasão discursiva, que pode ser traduzida em uma estratégia para sobrevivência dos negócios de maneira geral. O mais interessante de estudar as táticas e estratégias de organizações gastronômicas está justamente no fato de compor um estudo novo, pouco enfatizado e relacionado a uma atividade que vem crescendo - a construção do discurso gastronômico associado ao turismo. Além disso, neste caso estamos estudando um "polo gastronômico" muito novo e entre suas principais características está, indubitavelmente, a dinâmica. Aparecem, com muita frequência, restaurantes novos que tomam lugar daqueles que não lograram sobreviver no ambiente.

Neste estudo, foram percebidas duas fortes vertentes gastronômicas em Macacos que, aparentemente, são opostas, mas que coexistem naquele peque- 
no território. Essas tendências superficialmente opostas são: gastronomia internacional e a "cozinha comum" de Minas Gerais. O investimento na primeira é bastante frequente, mas quase nunca unidirecional, coexistem elementos e maneiras de fazer de diversas nacionalidades. E a segunda, tendência da regionalização da gastronomia, foi registrada como motivada pela demanda, como no caso de um proprietário de restaurante entrevistado (E03) que está substituindo seu empreendimento de gastronomia internacional (portuguesa e espanhola) por um de comida mineira, por ter visto a procura desse tipo de cozinha no local. Observamos, assim, que a cozinha regional e a internacional têm lugar marcado, mas pouco delimitado em Macacos. É interessante pontuar ainda a esse respeito que não há necessariamente uma distribuição espacial estrategicamente definida - reafirmamos aqui a paisagem pictórica da gastronomia. Contudo, foi possível perceber, com base em observação dos menus, associada às entrevistas, que há alguma relação entre as histórias de vida dos empreendedores e a escolha primeira dos produtos gastronômicos, apresentando-se, nesse aspecto, traços um pouco mais marcados. Mas reafirmamos que é apenas uma identificação primeira, porque, depois de algum tempo, todos os restaurantes adequaram suas propostas ao contexto. Redelinearam seus discursos e definiram novas estratégias de persuasão.

A culinária mineira que atualmente ganha um status de gastronomia ocupa mais fortemente as cozinhas de empreendedores autóctones. Há que se destacar ainda que isso ocorreu, mais especificamente, com os filhos de Dona Dica (citada no histórico deste trabalho), mas vem se intensificando em função do aumento do público que procura por esse típico reforçado com o discurso gastronômico. Nesse caso, identificamos alguns traços da gastronomia como representação de uma identificação familiar, decorrente das socializações na cozinha, entendendo-a, dessa forma, como ambiente familiar em si. Mas, simultaneamente, apreendemos essa sucessão familiar também como estratégica. No caso de um dos filhos, a menção ao nome da mãe e a constante associação da sua maneira de cozinhar à dela acabam por ser convertidas em uma estratégia para manter os antigos clientes da mãe e galgar um público que busca pela tradição, mas, claro, por uma tradição adequada à linguagem moderna.

Essa tradição vem associada ao requinte do discurso gastronômico, tanto é que, no caso de um dos filhos de Dona Dica, dono de um restaurante, as próximas mudanças na forma de organização do seu negócio estão diretamente associadas à perspectiva gastronômica. A socialização pelo discurso da gastronomia, no caso dos filhos de Dona Dica na cozinha, fica ainda mais evidente pelo fato de todos os sucessores serem homens, cada um gerindo um restaurante no local. Ao contrário do que se poderia esperar a respeito da cozinha comum, em que comumente observaríamos a socialização da mulher, nesse caso, os filhos que a ajudavam a 
servir os clientes e que agora administram os restaurantes revestem sua cozinha com discurso gastronômico. Eles transformaram alguns pratos típicos, incrementaram atrativos em seus estabelecimentos, de maneira que acabam atendendo diferentes públicos, até pela localização de seus restaurantes, mas todos eles mantêm o foco na gastronomia mineira. Nos próximos dois trechos, um dos filhos de Dona Dica fala sobre sua socialização e suas principais táticas na conquista de clientes pela gastronomia. Esse entrevistado é proprietário de um restaurante mais distante do centro do vilarejo, mas que recebe muito movimento:

Antes dela morrer, ela andou vindo umas vezes aqui e falou que talvez eu ia ficar no lugar dela na comida mineira, porque eu tinha tudo, a minha comida é igualzinha à dela. Assim... Depois que ela faleceu, inclusive, eu consegui ainda pegar os pessoal antigo que frequentavam o dela, que são os pessoal, hoje é da Vale, que era da MBR, né? Esse pessoal mais antigo, pessoal já acima de 80 anos, esse povo eu consegui trazer todo pra cá. E eles continuam comigo até hoje aí. Eu penso em ficar por aí... nesse cardápio mesmo, mas porém acrescentando isso que eu falei pra vocês: é ter um forno desses, não sei se vocês conhecem, de cupim também na área, fazendo todas broas que a gente sabe fazer, que é broa de fubá, que a gente aprendeu com minha mãe, né? Tudo o mais. [...] Queca, queca também é tradicional, minha mãe começou com isso. [...] Vamos tentar fazer. [...] Tudo feito na hora, você vai lá raspar o tacho na hora, pra saber que é coisa antiga, né? Que não é coisa industrial, nem nada (Eo8).

As táticas gastronômicas empreendidas por Eo8 e sua família não param na incorporação de (novos) antigos pratos nem na vitrina gastronômica: "tudo feito na hora, você vai lá raspar o tacho na hora, para saber que é coisa antiga”. A decoração do restaurante, a perfeita integração do ambiente da comida com o ambiente da produção dos alimentos e a relação direta com a natureza são os atrativos básicos do estabelecimento. A preocupação da família em fazer relações diretas dos pratos com os processos que envolvem seu feitio é uma marca da prática gastronômica, além da sugestão de bebidas adequadas e da exibição de alguns ingredientes-base. Mas não para por aí, o "mineirês" é falado naquele lugar, a preocupação do gestor em reafirmar um ambiente familiar, onde a esposa e as filhas (ainda jovens) participam, convida o cliente à integração com um típico mineiro da sala de visitas à cozinha.

Um caso diferente e interessante que representa a expansão da "cozinha comum" foi de um novo restaurante de comida mineira. Este, gerido por mulhe- 
res de uma família, surgiu há menos de um ano. A família se mudou para Macacos em busca de tranquilidade, e, nos primeiros meses na cidade, as mulheres que já trabalhavam em cozinhas em Belo Horizonte viram na comida mineira uma estratégia de sobrevivência. Isso porque até então havia pouquíssimos restaurantes de comida mineira, apenas aqueles dos filhos de Dona Dica. É então que elas surgem trazendo os mais tradicionais, atraindo não somente turistas, mas também a própria comunidade, por tratar-se de pratos com custos mais baixos, se comparados à maioria dos demais restaurantes do local.

Esse restaurante estava localizado no começo de sua atividade distante do centro, era frequentado mais pelo público local. As proprietárias em pouco tempo (três meses) observaram que seria promissor atender mais os turistas e alugaram um espaço na rua principal. Como é um dos mais novos restaurantes, quisemos saber como está sendo criado o cardápio. E a resposta foi imediatamente associada àquilo que chamamos aqui de uma construção de sentido por meio da interação. A comida como linguagem é escolhida com base na interação, nos topoi argumentativos, como é possível observar quando se perguntou sobre quem definiria os pratos em um dos restaurantes:

Os clientes dão a opinião, a gente senta e fala: Ah, eles pediram isso... A gente faz um teste: tantos clientes pediram, vamos ver se realmente tem saída. Então parte primeiro do cliente. E a nossa iniciativa é fazer um teste, né? Para ver se realmente vai dar certo (Eog).

Ao ser questionada sobre que pratos são solicitados pelos clientes, a entrevistada relata:

Sempre associado à comida mineira, porque aqui é pequeno. Então quem sai de BH ou de qualquer outro lugar para vir para cá está atrás disso: uma comida caseira, uma comida mineira, aquele temperinho de casa, aquela coisa assim, e a gente faz. Principalmente quem está em Belo Horizonte. Mas a semana é tão corrida, né? Faz um lanche só. O primeiro restaurante vazio que estiver mais rápido, mais em conta, como é só eu, então... Quem vem para cá vem atrás disso, da comida caseira, da comida mineira. Então é sempre em cima disso (Eog).

Aqui percebemos o retorno à relação do arraial com a comida mineira. As principais táticas das sócias desse restaurante consistem em chamar a atenção de um cliente inserido na vida moderna e corrida, para o retorno aos hábitos do interior, materializados na comida. E essa comida aparece relacionada diretamente à forma de tratamento da proprietária para com o cliente e também está relacio- 
nada ao espaço do restaurante. Analisemos primeiro a questão do atendimento. Trata-se de uma organização familiar que se destaca pela pessoalidade do tratamento entre as proprietárias, que são também funcionárias. Mas não somente isso, com o próprio cliente, observamos um tratamento mais pessoalizado, um jeito do generalizado mineiro: simpático e hospitaleiro. Voltando-nos para uma análise da decoração e para a organização do espaço, outros aspectos podem ser associados ao bucolismo de que se reveste o discurso da gastronomia mineira: o sentar na varanda, o ambiente aconchegante e rústico é observado no estilo das mesas e do balcão - de madeira rústica. Mas não somente isso, o restaurante é uma casa antiga, os clientes se acomodam na varanda da casa, os pratos são passados por uma janela. A placa com o nome do restaurante é um convite a entrar num espaço íntimo, na casa. No cardápio, ao contrário do que Giard (2003) definiu como construção do discurso gastronômico (o uso de nomes pomposos para os pratos), os nomes são bastante simples porque a estratégia das proprietárias está justamente na reafirmação de um típico, num contexto muito recente. Nesse caso especificamente, a estratégia está na reafirmação de uma cozinha comum, no contexto das comidas rápidas da vida moderna.

As expectativas da entrevistada (Eo9) são boas com relação à escolha da comida mineira como produto gastronômico. Isso se reflete nas pesquisas informais que elas fazem ao receber a opinião dos clientes, discutindo-a, como foi possível observar nos dois trechos anteriormente citados. Elas acreditaram no quão promissor seria o investimento nesse tipo de gastronomia e têm tido retorno, na medida em que as próprias sugestões dos clientes estão sempre associadas à comida mineira.

Quanto a essa gastronomia regional, alguns fatores devem ser considerados. Sendo ela muito relacionada à história e geografia do lugar, estaria implícita a maior facilidade na busca pelos ingredientes, sendo, nesse sentido, mais sustentável econômica, ambiental e socialmente. Isso porque ela permite a integração em rede de fornecedores locais para os ingredientes básicos. Segundo Franco (2004, p. 256), "a cozinha regional é geralmente auto-suficiente em termos de ingredientes", mas, "se esse fato lhe confere algumas virtudes, condiciona também sua monotonia e dificuldade em assimilar produtos, técnicas e idéias novas". Já a cozinha internacional:

[...] como observa Jean-françois Revel [...] é um conjunto de técnicas e princípios que permitem adaptação às possibilidades locais. É internacional graças ao talento de chefs que, dominando os fundamentos da cozinha clássica e usando de flexibilidade, podem reinterpretar receitas de diferentes origens (FRANCO, 2004, p. 257). 
Em Macacos, há essa perspectiva das reinterpretações, mas frequentemente ela fica silenciada. Isso ocorre porque, como se observou, muitos restaurantes disponibilizam seus pratos como legítimos das culturas que se propõem representar, mas, em decorrência das exigências do contexto ou da localização do estabelecimento, são obrigados a transformar pratos. A esse exemplo, têm-se as cozinhas espanhola, portuguesa, entre outras. Destacamos esse silenciamento porque ele seria uma questão paradoxal quando analisada no aspecto da aproximação das culturas, ou seja, seria contraditório em relação ao conceito de gastronomia internacional proposto por Jean-françois Revel, citado por Franco (2004). Entretanto, como observado in situ, os gestores e chefs dos restaurantes silenciam a adequação dos pratos de outras nacionalidades, temendo que se perca o tão almejado "status de internacional", que julgam ser atrativo. Outra questão que poderia ser entendida pela analogia da mudança de sentido ou da ressignificação é que, ao levar-se a gastronomia internacional para Macacos, não se adaptam apenas os ingredientes, mas também o preparo do alimento. É imprescindível considerar a questão do ambiente, da forma de organização da mesa, das bebidas que acompanham e, não se pode esquecer, da relação entre os sujeitos, desde os que ocupam a mesa até aqueles que a servem. Assim, a tão reconhecida "hospitalidade mineira" poderia ser considerada um tópos para a comunicação entre o processo de fazer e o de comer. Nesse sentido, uma vez mais se apresenta quão pictórico é o limite entre a gastronomia internacional e a local ou regional no lugar estudado.

Eu comi um prato que eu adaptei e fiz para o festival aqui, foi bom, é... um prato ele nem é angolano, ele é cabo-verdiano. [...] Mas aí leva frango, com quiabo, é uma misturada danada, sabe? É bom, mas é como se fosse uma comida da Bahia, né? Porque é uma comida de africano, né? Mas não podia fazer daquele jeito aqui também não. Mas aí [...] eu misturei angolano com cabo-verdiano, porque eu fiz com curry [...] (Ео3).

A proprietária e chef do restaurante deixa explícito na entrevista, não somente nesse trecho, que seus produtos gastronômicos provêm de suas experiências do comer no exterior. Ela diz que prefere cozinhar aquilo que gostou de comer. Nessas experiências, a entrevistada acaba por criar um discurso polifônico. Em um festival em Macacos, fez para concorrer um prato que é de origem caboverdiana; ao dizer que "ele nem é angolano", deixa subentendido que usou essa nacionalidade para chamar a atenção do cliente. Essa tática foi usada porque pouco se conhece sobre Cabo Verde, podendo não surtir efeito a colocação de sua origem. Na descrição dos ingredientes, associada à história do Brasil e da povoação da Bahia, está a primeira relação de interação sociodiscursiva apresentada. A analogia com a comida baiana foi usada para permitir a construção de 
sentido na relação entre a entrevistada e as pesquisadoras. Percebemos, assim, que a entrevistada, tanto na relação com as pesquisadoras como na relação com os clientes, preocupa-se com a construção do sentido, partindo dos estereótipos gastronômicos, pressupondo o desconhecimento de seu interlocutor em relação às diversas características gastronômicas com as quais trabalha. Em seguida, ela justifica a adequação de seu prato à socialização do seu público, deixa pressuposto que conhece o gosto de seu público e que, por esse motivo, adequou o prato ao gosto dele. Essa é uma tática bastante comum da inserção da gastronomia internacional. Ao final, a entrevistada ainda justifica a menção à origem "angolana" pelo uso de um ingrediente que, segundo ela, se inseriu no Brasil pela influência de Angola - o curry.

É interessante observar que os empreendedores que são também chefs tendem a fazer pratos com os quais tenham alguma identificação. No caso de Eo3, por exemplo, seu restaurante é de gastronomia portuguesa e espanhola, porque gosta, porque prefere trabalhar com pratos mais sofisticados:

Tem um prato que é típico daqui, que é o frango com ora-pro-nóbis. [...] Eu já fiz aqui, mas é um negócio, assim, que não combina muito comigo, primeiro porque eu não gosto de frango, então não combina comigo não. Eu só como peito (Eо3).

Esse é um restaurante que está sendo transformado, passará a servir apenas comida mineira, a proprietária passará a cozinha para o filho, já que ela não gosta de cozinhar "esse tipo de comida" (referindo-se à comida mineira). Assim, constatamos que não basta haver identificação apenas do produto oferecido com o gosto do proprietário. Mesmo a maioria dos restaurantes de comida internacional vem adequando sua oferta ao gosto e bolso mineiro. Aqueles que não se transformaram para atender às exigências do público acabaram se desfazendo, como está em processo o restaurante de Eo3.

Passemos ao caso de um restaurante de massas, existente na rua principal do arraial há doze anos. Foi muito interessante descobrir como esse restaurante bastante antigo, quando comparado à maioria dos outros, sobreviveu nesse ambiente tão dinâmico. Observemos o trecho a seguir no que tange à percepção da proprietária em relação ao ambiente:

Só tinha restaurante de comida mineira, aí, um ano antes de mim, abriu o Acervo da Carne, depois o Jerimun, depois eu abri. E... O imóvel ficou um ano para alugar. Ninguém queria alugar, não tinha nada em Macacos. Aí eu aluguei, e o pessoal começou a despertar para esse lado, né? E estou aí até hoje. Muitos já abriram, muitos já fecharam e eu continuo (Eıo). 
No caso de Eio, ela própria produz as massas; ainda que não tenha descendência italiana, sempre fez esse tipo de prato em casa. Sua principal tática, segundo a entrevistada, para manter a qualidade é o fato de ela própria fazer todas as massas. Assim, observamos a fidelização dos clientes que têm segurança sobre aquilo que vão comer. A entrevistada relatou que, ao longo do tempo, foram mudadas algumas ofertas no restaurante, algumas táticas, mas nada que comprometesse a qualidade de suas massas. É interessante apontar que, ao contrário de Eo3 que se negou a inserir no cardápio pratos para apenas agradar à sua clientela por não gostar deles, no caso de Eıo, apesar de ter resistido por muito tempo, por exemplo, à comercialização da batata frita, cedeu ao perceber que sem ela perdia muito público.

Depois de ter falado sobre a mudança de público ao longo dos doze anos de atividade no local, Eıo explicitou algumas adequações no discurso usado no restaurante para permitir sua sobrevivência, vejamos algumas delas:

A batata frita [...] a linguiça com mandioca, fui obrigada a adaptar porque senão eu fechava as portas. Mas a minha massa continua mantendo, manter, né? Lógico. Mas eu fiz resistência, muita resistência quanto à batata frita. Porque, na verdade, eu não posso reclamar porque na verdade é uma delícia, não é ruim, é muito bom. Mas porque meu perfil é restaurante e a ideia não era abrir as portas e ficar o dia inteiro tomando cerveja, né? O pessoal faz muito isso. O pessoal de dia vem almoçar e vai embora, sabe? Eu consegui manter, porque aqui é um restaurante, não é um boteco, sabe? Eu consegui manter isso (Eio).

A ideia da obrigação permite inferir o não desejo e a rechaça. Assim, identificamos a oferta de petiscos comuns em bares como uma tática de extrema necessidade, para adequar a linguagem do restaurante à do público. É interessante observar como que nesse caso a comida aparece como linguagem. Observemos: a batata frita seria um léxico comum da linguagem do cotidiano do público, mas ele traz conotações frequentemente associadas à ideia do bar (na construção de sentido da proprietária), que, por sua vez, imprime o estereótipo da "bebedeira", associada, por fim, à noção de vulgaridade. Entretanto, por reafirmar o lugar da argumentação - seu restaurante e não um bar qualquer -, Eıo, ao desenhar o tópos argumentativo, acaba por desenvolver táticas em que transforma o sentido do léxico "batata frita”. É dessa forma que se apropria do discurso de outrem mudando seu sentido, desenvolvendo, por conseguinte, uma estratégia de persuasão do cliente.

Não é, entretanto, só na batata frita ou na incorporação de petiscos "de boteco" que percebemos a polifonia. Ao passarmos na frente do restaurante, o que de fato nos chamou a atenção foi um ambiente aconchegante, a fachada pintada com cores da bandeira da Itália, o nome envolvendo as massas e um quadronegro com a seguinte informação, escrita com giz: "Temos feijoada”. Foi naquele 
primeiro momento que se fez mais instigante realizar a entrevista naquele restaurante, onde observamos claramente a polifonia como estratégia para conseguir novos clientes, sem perder os antigos.

Outro interessante caso da mescla das vozes no discurso gastronômico está no talvez mais essencial restaurante de comida internacional. Esse restaurante administrado por um casal (um norueguês e uma descendente de italianos), em que se comercializam trutas e massas, é um convite ao diferente e ao mundo das estratégias gastronômicas. Entre os restaurantes visitados, esse foi considerado o mais requintado, mas não por isso menos pessoal. O espaço é uma casa bonita e elegante, onde diversas artes coexistem, da cozinha, passando pela decoração e chegando até a literatura. Mas o espaço é mantido ainda como casa, as mesas se distribuem desde o jardim à sala de estar, e os donos ainda moram no andar superior do imóvel. A escolha inicial do cardápio esteve também relacionada à identidade dos proprietários. O foco nesse restaurante é na cozinha mediterrânea, uma cozinha que é classificada como mais saudável, atendendo a uma demanda crescente cada vez mais preocupada com a saúde e que entende a alimentação como a base de uma vida saudável e como possibilidade de prazer. Todavia, conforme foi possível observar, os proprietários já pensam em uma adequação para possibilitar a diversificação de públicos, mantendo a boa comida, mas proporcionando pratos menos trabalhosos ou com ingredientes que possam ser encontrados com mais facilidade.

Alguns pratos permanecem, sim, o mais tradicional que é a truta norueguesa, que é receita do proprietário do restaurante, uma torta de batata que era da mãe dele... Agora os outros a gente foi modificando, aprimorando até chegar no que a gente queria. A gente incluiu risoto no cardápio, agora no inverno a gente vai tentar fazer a batata Roche a partir da semana que vem, como prato principal, porque o público da noite é bem diferente do público do dia... né? Então a gente vai tentando adaptar, né? [...] Eu já tenho uma clientela muito tradicional durante o dia, né? Então, mais família, o pessoal mais velho, mais tranquilo... E à noite as pessoas estão descobrindo mais Macacos e vem muito casal de jovem, é gente que vem para o final de semana e tal... E às vezes essas pessoas elas não querem jantar, elas não conhecem às vezes um pouco de gastronomia, elas nem têm dinheiro, né? Mas quer comer num lugar bacana, quer ficar num lugar legal, então a gente resolveu dar uma remoçada no cardápio para a noite. Vamos manter duas trutas, que é a nossa especialidade, mas aí vamos começar com dez opções de batata Roche, algumas opções de caldo, para dar uma remoçada mesmo. Porque acho que é sempre válido quando as pessoas querem sair de casa para comer bem e não necessariamente têm que pagar caro, né? Ou não têm que sair para jantar para ficar num lugar legal. Então a gente vai modificar em função disso (Eog). 


\section{ENTRE NOVOS E TRADICIONAIS SABORES: A GASTRONOMIA COMO ATRATIVO TURÍsTICO}

A influência da comida mineira se deve a uma série de fatores que começam pela história da culinária como produto em Macacos. Dona Dica foi a precursora da comercialização da comida direcionada para o turismo. Ao servir pratos que eram feitos em seu cotidiano, os pratos da cozinha comum, aos motoqueiros que faziam trilhas na região, começava o embrião do que hoje consideramos turismo gastronômico. A comida passava a atrair cada vez mais interesse de outras pessoas que não motoqueiros. Os filhos de Dona Dica seguiram os preceitos das organizações familiares e continuaram com o negócio. Ainda mais, três deles abriram novos negócios, dos quais alguns familiares são funcionários. Todos optaram pelo mesmo ramo e com mais ou menos a mesma oferta gastronômica, diferenciando-se na decoração e no público-alvo. Alguns restaurantes e bares - que não são de filhos de Dona Dica - também trabalham com alguns ícones da comida mineira e ainda com alguns petiscos comumente encontrados em quaisquer bares e restaurantes, quais sejam: carne de sol com mandioca, filé com fritas, filé com mandioca e carne cozida, entre outros.

É interessante perceber, no contexto dos restaurantes de "comida típica mineira", que há incorporação de novas estratégias, entendendo que a comida se transformou também em produto e, portanto, em objeto da sobrevivência do negócio. Observamos que os empreendedores passaram a agregar valores à comida, transformando o restaurante em um espaço de experienciação. A esse exemplo, um dos filhos de Dona Dica, além de ter ambientado seu restaurante com motivos mais rústicos, serve gratuitamente cachaça e cigarro de palha, elementos muito comuns em Minas Gerais e que frequentemente aparecem como símbolos de uma mineiridade. Ademais, ele já delineia novas estratégias que tendem a transformar ainda mais seu restaurante em um atrativo turístico gastronômico.

Com esta análise empírica, acreditamos ter contribuído para o deslindamento de táticas e estratégias associadas à comida como produto, sem esquecer que ela é cultural. No que tange às táticas e estratégias, em alguns casos é possível observar a tentativa de projeção da identidade gastronômica familiar como motivadora do negócio. No entanto, ela não é rígida. Em virtude da constante interação com o outro, como o cliente, os pratos são transformados, e, nos restaurantes, desenvolvem-se táticas com o propósito de atender às exigências do público. Percebemos incorporações de discursos, visando às estratégias de persuasão desses sujeitos do qual dependem os negócios. 
É fato que a alimentação é um elemento cultural, e, sobre isso, tanto não há dúvidas que muitos processos culinários estão sendo registrados como patrimônio imaterial. É de conhecimento comum também que a alimentação está relacionada aos espaços e às pessoas, sendo imprescindível considerar o uso dos alimentos como algo cultural, inserido numa construção social e, por conseguinte, possível delineador de identidades culturais. Entretanto, neste estudo, a comida como produto recebe mais sentidos, no meio cultural ela é também produto. Ela passa a ser usada dentro de um discurso cultural para converter-se em produto gastronômico-turístico. No uso de elementos típicos da região, típicos da casa dos proprietários ou chefs (oriundos de distintas regiões do mundo), estão uma aproximação de culturas e a construção de discursos.

Observamos, ao final desta pesquisa, que a gastronomia está intrinsecamente relacionada com o turismo no locus. Em decorrência disso, vários sentidos foram socialmente construídos em torno dela. As próprias representações delineadas pelos empreendedores em relação à gastronomia variam de acordo com o "lugar" de onde enunciam. Assim, a construção dos sentidos em torno da gastronomia em Macacos vai ao encontro da teoria dos topoi argumentativos (DUCROT, I989), segundo a qual os argumentos e os sentidos são construídos em lugares, ou em espaços simbólicos, que dependem do compartilhamento de valores. A exemplo, podem ser citados os empreendedores forasteiros que passam a assumir Macacos como "seu lugar", já que a sobrevivência desse grupo provém da atividade ali realizada. E, nessa representação, aparecem também, por meio de observação e da fala sobre suas ações, as táticas e estratégias empreendidas, voltadas para o requinte mesclado ao rústico (implícito no local) e ainda associado ao jeito mineiro de receber.

Já para empreendedores autóctones, que são poucos, as representações em torno do lugar estiveram frequentemente associadas à competitividade entre os restaurantes e a reafirmação de um típico, mas inseridas no discurso moderno em que esse típico é relido para apresentação ao cotidiano da vida moderna. Acreditam ter seu espaço invadido pelos forasteiros, e suas principais estratégias são voltadas para a reafirmação identitária em seu empreendimento, em torno do simbolismo da família e da comida típica. Fazem questão de destacar a rusticidade do ambiente e/ou a tipicidade dos pratos.

Em meio às análises das ofertas gastronômicas, se tomamos como referência os gestores das organizações, observamos muito fortemente a polifonia que representa a gastronomia. Constatamos na análise dos cardápios e nas conversas com os proprietários que a elaboração dos pratos está frequentemente associada a alguns fatores, entre os quais se destacaram: história de vida dos chefs (em geral, os próprios proprietários), história de vida dos gestores e indicações de interesse dos clientes. A mistura de elementos motivadores da composição dos 
cardápios, associados à dinâmica das histórias de vida, permitiu chegar à polifonia gastronômica, uma vez que muitas das ofertas gastronômicas trazem em si referências discursivas e históricas.

A pergunta feita no histórico de Macacos deve ser respondida neste item, pois até aqui já se deslindou um panorama da gastronomia no local. Macacos tem sido apresentado como polo gastronômico pelos empreendedores ali estabelecidos, sendo sua maioria composta por pessoas que não são do lugar, ou seja, que não foram criadas ou não tiveram sua socialização primária no distrito. Mais recentemente, esse discurso em torno do polo gastronômico vem sendo apropriado também pelos proprietários autóctones, o que é materializado também nas novas estratégias e táticas desenvolvidas em suas organizações. Esse fato é sempre escondido em meio aos discursos dos empreendedores, que sempre apresentam essa figura metonímica, da parte pelo todo, como forma de validar a caracterização do distrito, passando ao interlocutor a imagem de que há uma pretensão generalizada, na tentativa de forjar uma identidade turística. Entendemos por meio da pesquisa realizada que não necessariamente ser um polo gastronômico seja um interesse da maioria, mas sim da parcela diretamente beneficiada.

Observamos que o desenvolvimento da gastronomia como produto está intrinsecamente relacionado ao turismo, e, por isso, os sentidos da gastronomia em Macacos são diferenciados de acordo com os grupos. Para os empreendedores, ela é sobrevivência, é também uma forma de contribuição, na medida em que faz movimentar a economia e gerar empregos.

Enfim, entendemos que atualmente os empreendedores metonimizados na figura de "Macacos" querem se apresentar como polo gastronômico e têm grandes chances de fazê-lo, tendo como chamariz essa própria coexistência do tradicional, do exótico, do moderno e do artístico. Mas seria interessante deixar de tratar a gastronomia apenas como produto, elevando-a à possibilidade de intercâmbio cultural, deixando que os pratos de fato comuniquem, já que compõem um discurso. Para a organização dos bares, dos restaurantes e das pousadas, propomos o estabelecimento de redes entre si, o que facilitará a produção cultural do alimento, além de movimentar a economia local, a fim de incentivar tanto o público dos meios de hospedagens a frequentar diferentes restaurantes como o público dos restaurantes a conhecer os meios de hospedagens.

Como contribuição aos estudos organizacionais de forma geral, o presente estudo reforçou novas formas de compreender a formação de estratégias nas organizações. Em primeiro lugar, entendendo-as como práticas, que se constroem no cotidiano pelo fazer de todos os sujeitos que se encontram no território do grupo estrategista. Em segundo lugar, o fazer estratégico se encontra misturado a uma bricolagem de práticas cotidianas, muitas delas divergentes 
do objetivo dominante, ou seja, táticas daqueles destituídos de poder territorial. Um terceiro ponto é a visão das estratégias e táticas como práticas discursivas e polifônicas que operam continuamente na construção e reconstrução dos significados. Significados estes que compõem e projetam certas identidades àqueles que se encontram no interior do território e àqueles de fora. Por fim, destaca-se aqui a importância de se explorar a relação entre estratégia e espaço - físico e simbólico. Ambas as dimensões estão em constante interação dialética, sendo o espaço o lugar de onde a estratégia surge e a estratégia a origem de transformação para os significados espaciais.

É importante dizer, ao final dessas contribuições, que não houve pretensão, de maneira alguma, de esgotar os temas relativos a gastronomia, práticas estratégicas e turismo em Macacos, tanto pelo espaço destinado a este trabalho como pela dinamicidade das organizações socioespaciais, que inviabilizariam obviamente esse esgotamento. Essa afirmação vai ao encontro da perspectiva abordada dos sentidos da gastronomia, que não são fixos, porque são dialógicos e social e cotidianamente construídos. Assim, relembramos como se caracteriza a "metodologia científica de Bakhtin": "nada lhe parece acabado; todo problema permanece aberto, sem fornecer a mínima alusão a uma solução definitiva" (BAKHTIN, I999, p. Iо).

Como possibilidades de pesquisas futuras, apontamos: I. o estudo das representações sociais em torno das mudanças físicas e simbólicas em determinado espaço, tanto em organizações como em locais mais amplos, cidades e arranjos produtivos; 2. a realização de uma pesquisa de caráter histórico com antigos moradores de Macacos, fazendo uma investigação dos elementos da culinária que permaneceram e aqueles que se transformaram; 3. uma análise da relação entre os tropeiros, as viagens do século XIX e a cozinha comum da contemporaneidade em São Sebastião das Águas Claras; 4. um estudo da demanda, observando quais as motivações dela; e, por fim, 5. a relação da indústria cultural e a patrimonialização, fazendo menção aos estudos da moda e do status em relação às viagens turísticas, entre outras várias possibilidades.

\section{REFERÊNCIAS}

BAKHTIN, M. Marxismo e filosofia da linguagem: problemas fundamentais do método sociológico na ciência da linguagem. São Paulo: Hucitec, I999.

BRITO, T. M. A. de. A importância das escalas espaciais para compreensão do processo de globalização. Geografias, Belo Horizonte, v. 2, n. I, p. 93-Io6, jan./jun. 2006.

BURNS, P. M. Turismo. In: Turismo e antropologia: uma introdução. São Paulo: Edições 
CERTEAU, M. A invenção do cotidiano. Petrópolis: Vozes, I994.

DRUMMOND, Â. A festa acabou? Macacos em Revista, v. I, 2008.

DUCROT, O. Argumentação e topoi argumentativos. In: GUIMARÃES, E. História e sentido na linguagem. Campinas: Pontes, I989.

FRANCO, A. O alimento no século XX. Internacionalização - mcdonaldização. In: De caçador a gourmet: uma história da gastronomia. São Paulo: Senac, 2004.

FREDERICO, R. L R.; MÓDOLO, C. M. Identidade cultural nas imagens da mídia especializada em gastronomia. In: FÓRUM DA DIVERSIDADE E IGUALDADE: CULTURA, EDUCAÇÃO E MÍDIA, Bauru, 2007. Anais Eletrônicos... Disponível em: <http://www.faac.unesp.br/publicacoes/ anais-comunicacao/textos/23.pdf>.

FREITAS, C. L. Turismo, política e planejamento: estudo do circuito turístico do diamante no Vale do Jequitinhonha, em Minas Gerais. 2008. Tese (Doutorado)-Universidade Federal de Minas Gerais, Belo Horizonte, 2008.

FURLANETTO, M. M. Argumentação e subjetividade no gênero: o papel dos topoi. Linguagem em (Dis)curso - LemD, Tubarão, v. 6, n. 3, p. 519-546, set./dez. 2006.

GIARD, L. Cozinhar. In: CERTEAU, M.; GIARD, L.; MAYOL, P. A invenção do cotidiano 2: morar, cozinhar. Petrópolis: Vozes, 2003.

GUIA DE MACACOS. Disponível em: <http://www.guiamacacos.com.br/festivalinverno.html>. Acesso em: Io dez. 2008.

MINAS BIER FEST. Disponível em: <http://www.minasbierfest.com.br/home.htm>. Acesso em: Io dez. 2008.

MONTANARI, M. Comida, lenguaje, identidad. In: MONTANARI, M. La comida como cultura. España: Ediciones Trea, 2006. p. 93-II5.

MONTORO, T. A construção de imagens da gastronomia nos cadernos de turismo dos jornais brasileiros. In: ARAÚJO, W. M. C; TENSER, C. M. S. Gastronomia: cortes e recortes. São Paulo: Senac, [s. d.].

O DEBATE. Disponível em: <http://www.odebate.com.br/index.php?option=com_content\&task= view\&id=939I\&Itemid=93>. Acesso em: $\mathrm{I}^{\mathrm{o}} \mathrm{dez} .2008$.

OLIVEIRA, S. La importância de la gastronomia en el turismo: un ejemplo de Mealhada - Portugal. Estudios y perspectivas en Turismo, Buenos Aires, v. I6, n. 3, p. 26I-280, jul. 2007.

PELEGRINI, L. Os pés alados de Mercúrio: relatos de viagens à procura do self. São Paulo: Axis Mundi, I997.

QUEIROZ, M. N. Rompendo os tapumes: uma proposta de interação vivenciada através da restauração na comunidade de São Sebastião das Águas Claras/MG. 2003. 235 f. Dissertação (Mestrado em Artes Visuais)-Universidade Federal de Minas Gerais, Belo Horizonte, 2003.

RODRIGUES, G. Tudo começou com a Dona Dica. Macacos em Revista, v. I, 2008.

STAM, R. Bakhtin: da teoria literária à cultura de massa. São Paulo: Ática, I992.

VERGARA, S. C. Métodos de pesquisa em administração. São Paulo: Atlas, 2005.

WANDSCHEER, E. A. R.; LINDNER, M.; SOUZA, M. de. As festividades e a alimentação enquanto elementos de identidade cultural no município de Silveira Mardins - RS. Para Onde?, n. 2, p. 8-26, jan./jun. 2008.

WÖLFFLIN, H. Conceitos fundamentais da história da arte: o problema da evolução dos estilos na arte mais recente. Tradução João Azenha Júnior. 4. ed. São Paulo: Martins Fontes, 2000. 